\title{
Crise na educação médica? Um ensaio sobre o referencial arendtiano
}

This essay contributes towards the context of transformations in medical education in Brazil in the light of the thinking of the political philosopher Hannah Arendt. This author makes a critical reading of modernity, pointing out its context of crisis and how this is reflected in areas such as education and politics. Starting from reflections on the crisis in education, the breakdown of tradition and loss of authority, we use Arendt's ideas to analyze medical practice and its training, which is guided mainly by the biomedical model and other manifestations of the modern world. Finally, we emphasize the need to include categories such as responsibility, judgment and reflective thinking in medical education, which this author analyzed in her late work.

Keywords: Medical education. Politics. Modern history 1601 -
Trata-se de um ensaio que contribui para o contexto de transformações na educação médica no Brasil à luz do pensamento da filósofa política Hannah Arendt. A autora faz uma leitura crítica da modernidade, apontando seu contexto de crise e quanto esta se reflete em áreas como as da educação e da política. Partindo das reflexões sobre a crise na educação, a ruptura com a tradição e a perda da autoridade, trazemos seu pensamento para uma análise sobre a prática médica e sua formação, pautadas, sobretudo, pelo modelo biomédico e outras manifestações do mundo moderno. Por fim, ressaltamos a necessidade de se trabalhar, na educação médica, com categorias como responsabilidade, julgamento e pensamento reflexivo, que foram objetos de análise da autora, já na fase final de sua vida.

Palavras-chave: Educação médica. Política. História moderna 1601-

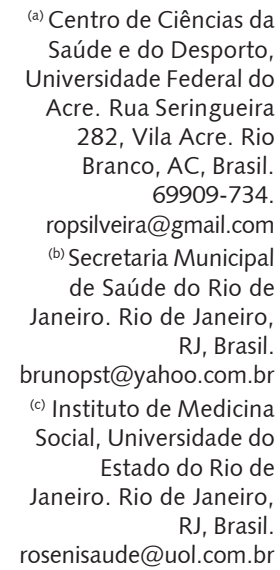


O campo da medicina não é algo estático, se constituindo como um espaço social onde os atores estão em meio a tensionamentos com interesses diversos, envolvendo a prática médica, a produção de conhecimento e o campo da formação. As escolas médicas constituem centros de seleção e legitimação da prática médica, ou seja, as inovações passam por um processo de aprovação pelas instituições de ensino para serem consideradas pelo campo. Este papel é exercido de diversas maneiras, sendo a mais comum: a incorporação da "inovação prática" ao currículo do curso de medicina".

A partir dessa assertiva, podemos pensar numa primeira indagação pertinente a esse ensaio: é possível falar em crise na educação médica? Embora, no senso comum, a palavra crise esteja associada a um contexto negativo, para a filósofa Hannah Arendt, crise se refere a um momento ótimo para intervenção, quando se desestabiliza o que era estável, um momento crucial onde as coisas se definem². Considerando as transformações na educação médica vivenciadas nas últimas duas décadas, tensionando o modelo hegemônico na tentativa de formar médicos mais próximos às necessidades da população, diríamos que é possível afirmar que há, de fato, uma crise na educação médica no Brasil.

A concepção de crise como oportunidade permite construir respostas a um conjunto complexo de novas demandas sociais e de saúde, para as quais a formação médica tradicional, com base no modelo biomédico, se mostra limitada. Essas demandas são decorrentes de mudanças no perfil demográfico e de crescentes industrialização e urbanização, fenômenos relativamente recentes no país, que fazem emergir outros problemas de saúde pública, como: violência, deterioração das relações de trabalho, desemprego e pobreza, além do aumento da prevalência de doenças crônico-degenerativas e de sofrimento psíquico, no que Luz ${ }^{3}$ caracteriza como "fragilidade social".

Esses fenômenos têm colocado em questão a hegemonia da biomedicina como modelo produtor de práticas e saberes médicos, expondo limitações, gerando frustração nos profissionais e insatisfação da população com a assistência à saúde prestada ${ }^{3}$. Soma-se a isso o expressivo desenvolvimento da cadeia produtiva ligada à medicina, tornando o campo da saúde um espaço fértil para ampliação de uma lógica baseada no lucro e no acúmulo de capital, tendo como maior expressão a indústria farmacêutica e o complexo médico-financeiro, como um dos setores que mais lucra no mundo ${ }^{4}$.

A formação de profissionais é ação fundamental para gerar respostas a essa problemática, pois possibilita incluir novas práticas de ensino-aprendizagem que trabalhem os conhecimentos e as atitudes necessárias para lidar com essa nova realidade. Considerando os movimentos recentes da formação em medicina, essa premissa nos leva a uma segunda indagação: trata-se de uma crise na ou da educação médica?

As últimas duas décadas têm sido de intensos debates no contexto brasileiro, com avaliação de escolas médicas, construção de novas Diretrizes Curriculares Nacionais (DCN) e modificação nos modelos pedagógicos ${ }^{5,6}$. Elementos das novas tendências da educação têm sido construídos e testados, e novos cenários de práticas têm se apresentado. Nota-se uma efervescência no campo, tendo em vista o crescente número de trabalhos publicados, trazendo contribuições para tornar ainda mais consistente esse processo de transformação $0^{5,7}$.

Desde a década de 1950, já eram apontadas críticas ao modelo de formação médica. Essas ganharam maior expressividade nos anos 1970-80, nas escolas que já sinalizavam a necessidade de reforma curricular, muitas vezes sustentadas pelos movimentos da Medicina Integral, Preventiva e Comunitária. Os projetos, a maior parte deles financiados por organizações internacionais, foram abarcados como a estratégia de Integração Docente-Assistencial (IDA), amplamente analisados por Marsiglia ${ }^{8}$.

No início dos anos 1990, foi implantado, em algumas universidades brasileiras, o Projeto UNI, que promovia articulação entre o ensino e o serviço, com a participação ativa da comunidade. O Projeto Uni foi financiado pela Fundação Kellogg e abrangeu instituições da América Latina e Caribe ${ }^{9}$. Posteriormente, as iniciativas UNI e IDA se reuniram formando a Rede UNIDA, que se constitui, atualmente, num importante fórum de discussão sobre as transformações no cenário da educação dos profissionais de saúde no Brasil ${ }^{10}$.

Outro movimento na década de 1990, a Comissão Interinstitucional Nacional de Avaliação das Escolas Médicas (CINAEM), propôs um processo de avaliação transformadora das escolas médicas que partisse das próprias instituições ${ }^{11}$. Esse movimento identificou os principais problemas da formação 
médica, gerando um processo de mudança que impulsionou a construção das novas DCN para os cursos de medicina.

Entendemos que, nessa trajetória de rupturas e continuidades, apresenta-se inovadora a formulação das novas DCN. Desde sua publicação, em 2001, o Ministério da Saúde tem influenciado no sentido de ordenar a formação de profissionais para atuação no SUS e implantado programas de incentivo de caráter indutório para acelerar os processos de mudança ${ }^{7}$. Citamos, como exemplos desse processo de ordenação da formação médica, os Polos de Educação Permanente, o AprenderSUS, o Promed, o PróSaúde e o PET-Saúde. Em linhas gerais, todas essas políticas e programas objetivam estimular processos de mudança na formação de profissionais de saúde, com ações como: a diversificação dos cenários de aprendizagem, articulação com os serviços e criação de ações interdisciplinares na graduação, tendo os princípios do SUS e as DCN como alicerce.

Todo esse processo vem acontecendo no sentido de responder a um anseio da sociedade pela formação de profissionais que possam se aproximar das necessidades da população e do sistema de saúde, pois, até então, a mesma era guiada por um pensamento típico da modernidade (modelo biomédico) e por interesses decorrentes desse modelo. Dessa forma, há elementos suficientes para pensarmos que se trata de uma crise na educação médica, pois não se trata de uma desestruturação no campo, mas da manifestação da crise da modernidade na educação médica. Trata-se, então, de um momento oportuno para a emergência de experiências inovadoras que possam transformar o modelo pedagógico das escolas e da formação como um todo.

A partir desse entendimento, o Laboratório de Pesquisas sobre Práticas de Integralidade em Saúde (Lappis/IMS/UERJ) vem desenvolvendo, desde 2002, estudos sobre a formação de profissionais para o SUS, buscando compreender como a integralidade pode ser apropriada como eixo fundamental de construção de saberes e práticas do cuidar e da promoção da saúde ${ }^{12}$. Cabe ressaltar que a noção de integralidade também tem sido afirmada na perspectiva de articular um conjunto de sentidos que visam orientar a organização das práticas no cotidiano das instituições de saúde, abrangendo tanto os processos de trabalho como as ações de formação em saúde ${ }^{13}$.

Nessa trajetória de pesquisas, constatou-se a necessidade de refletir sobre a inclusão de outros referenciais teóricos capazes de auxiliar a análise do processo de transformação na educação médica. Apoiados nas contribuições de Hannah Arendt, propomos um debate para compreender o contexto de crise e apontar alguns caminhos que julgamos interessantes a partir de categorias trabalhadas pela autora.

O referencial teórico que norteia este texto tem um caráter inovador, pois apresenta outros olhares sobre o que a autora denomina de crise da modernidade, com conceitos-chave que possibilitam uma visão crítica tanto da educação como da medicina, e de sua interface no campo da educação médica.

Embora Arendt tenha dedicado seus estudos ao campo da filosofia política, assumimos como importantes suas contribuições para a discussão da educação. Para caracterizar esse debate, partimos de um texto clássico da autora, denominado "A crise na educação", que apresenta um conjunto de reflexões pertinentes e atuais, que fazem conexões com conceitos fundamentais de sua obra, tais como: liberdade, autoridade e tradição ${ }^{14}$. Em seu único texto publicado que remete diretamente à educação, Hannah Arendt não se preocupa com os processos pedagógicos, mas com concepções e pensamentos que dão base ao campo, e em que medida a crise da modernidade nele repercute. Essas reflexões podem qualificar o debate sobre as tendências de mudança na formação médica, havendo possibilidades para a emergência de novos olhares para a construção de uma prática mais humana da medicina.

Arendt se debruçou sobre o tema das atividades que praticamos no mundo, em especial, a política. No entanto, as perplexidades vivenciadas pela pensadora frente ao totalitarismo da Alemanha nazista e o Holocausto até o julgamento de Adolf Eichmann no início dos anos 1960, determinaram os rumos dos questionamentos da autora no que diz respeito à conduta e à ação humanas e as relações entre política e ética. Como aquilo pôde acontecer numa Alemanha com padrões morais supostamente firmes e estáveis? Como pessoas como Adolf Eichmann e tantos outros serviram a tal maquinaria, sem a capacidade de refletir sobre o que estavam fazendo, como "dentes de engrenagem", dizendo-se inocentes e alegando, burocraticamente, "obediência a ordens superiores"? Partindo desses 
questionamentos, Arendt desenvolveu reflexões que motivaram a análise de categorias como responsabilidade e julgamento ${ }^{15}$.

Não se trata aqui de fazer uma transposição do pensamento da autora para o contexto atual, mas de utilizar seu referencial teórico-conceitual para discutir as transformações na educação médica, tanto na caracterização de uma "crise na educação", quanto nas conexões com as categorias trabalhadas pela autora no campo da política.

\section{Educação no pensamento de Hannah Arendt}

Em sua análise mais ampla sobre a crise da modernidade, um dos aspectos em que a autora se debruça especificamente é a sua repercussão na educação.

Educação, para Arendt, é estritamente ligada ao fenômeno da natalidade. Para ela, nascer para a vida é diferente de nascer para o mundo, sendo que nascemos para a vida pelo nascimento e, para o mundo, pela natalidade. "O mundo - artifício humano - separa a existência do mundo de todo ambiente meramente animal; mas a vida, em si, permanece fora desse mundo artificial, e através da vida o homem permanece ligado a todos os outros organismos vivos" ${ }^{16}$. Nascemos para a vida, para crescermos em nossa subsistência, mas, também, para um mundo que é um conjunto de realizações humanas prévias a esse nascimento. O fato de que nascemos para o mundo é, para Arendt, a essência da educação.

Para a autora, a natalidade dá a oportunidade da emergência do novo, da recriação do instituído. Um novo mundo se inicia por aqueles que são, por nascimento e natureza, novos. É através da natalidade que o mundo está em constante renovação.

A autora chama a atenção para a importância da dimensão temporal do processo educativo, na qual história, realidade e responsabilidade com o futuro se interconectam. Ou seja, o reconhecimento da memória dos saberes e práticas já construídos no passado abrem possibilidades de exercer a liberdade para mudar o futuro.

O papel da escola, ao acolher a criança e o jovem, é realizar a mediação entre a esfera privada da família e a sua atuação no mundo através da atitude política, quando adulta, na esfera pública. Dessa maneira, a educação é classificada, pela autora, como um fenômeno pré-político. A função educacional primordial seria apresentar o mundo, para que esse ingressante possa promover, com liberdade, sua ação política no espaço público, com vistas a recriá-lo. Para isso, é necessário que estejamos com os olhos no passado e que este seja a base para a transformação do futuro, pois os novos se inserem num mundo que já existe, e devem conhecê-lo para nele terem a possibilidade de realizar algo novo.

Para a autora, a crise na educação tem estreita ligação com dois condicionantes: a ruptura com a tradição, ou seja, com nossa atitude em relação ao passado e, sobretudo, com a perda da autoridade.

O problema da educação no mundo moderno está no fato de, por sua natureza, não poder esta abrir mão nem da autoridade nem da tradição, e ser obrigada, apesar disso, a caminhar em um mundo que não é estruturado nem pela autoridade nem tampouco mantido pela tradição. ${ }^{14}$

Transformar o mundo não significa romper com a tradição, pois com a perda da tradição não se perde o passado, mas se perde "o fio que nos guiou com segurança pelos vastos domínios do passado" 17. A tradição não é o passado, mas a memória, que resguarda a profundidade da existência humana. Sem memória, sem recordação, não há profundidade. É como "pensar sem corrimão", ou seja, sem o auxílio da tradição.

A noção de autoridade para Arendt está relacionada com o reconhecimento, e se refere à relação com nossos mestres e antepassados, possíveis mediadores da tradição e dos tempos passados e exemplos de ação no mundo presente. Assim, se configura uma "autoridade legítima", e a perda da mesma refere-se à falta de responsabilidade e despreparo dos adultos em apresentar o mundo adequadamente ${ }^{18}$. 
Educar era simplesmente 'fazer-vos ver que sois inteiramente dignos de vossos antepassados', e nesse mister o educador podia ser um 'companheiro de luta' ou um 'companheiro de trabalho' por ter também, embora em nível diverso, atravessado a vida com os olhos grudados no passado. Companheirismo e autoridade não eram nesse caso senão dois aspectos da mesma substância, e a autoridade do mestre arraigava-se firmemente na autoridade inclusiva do passado enquanto tal ${ }^{14}$.

Esse ponto de vista em nada evoca o uso de métodos violentos ou coercitivos, que se traduziria em "autoritarismo". Pelo contrário, nesse caso, não é um que imprime autoridade ao outro, mas é o outro quem Ihe confere autoridade. É uma autoridade reconhecida e, desta forma, legítima. Ao não ter autoridade para apresentar o mundo, os adultos privam a criança do alcance da liberdade, pois a mesma fica "sujeita a uma autoridade muito mais terrível e verdadeiramente tirânica, que é a tirania da maioria"14.

A autora se refere a uma sociedade de massas e exemplifica a perda da autoridade com a anulação das diferenças entre adultos e crianças. Partindo desse pensamento, Arendt faz uma análise crítica tanto das correntes progressistas como das tecnicistas da educação. Por um lado, pressupõem as crianças como protagonistas do processo de aprendizagem, por outro, consideram-nas como ferramentas para o mercado de trabalho.

No Brasil, o referencial progressista da educação é identificado, sobretudo, no movimento conhecido como Escola Nova. Nestas correntes, há uma tendência a igualar professor e aluno, desfazendo essa hierarquia nas relações pedagógicas ${ }^{19}$. Uma das "ilusões escolanovistas" talvez seja a ênfase excessiva na experiência prática pessoal, na busca de constante inovação, acarretando risco potencial em descuidar da apropriação do conteúdo das teorias já conhecidas tradicionalmente ${ }^{20}$.

Para Arendt, o papel da escola e do professor é apresentar o mundo, responsabilizando-se por ele. O professor busca no passado fatos importantes e aspectos culturais que merecem ser lembrados e/ou preservados, apresentando aos alunos o mundo como ele é, e não como deveria ser. Com base nessa tradição é que temos a liberdade para mudar o futuro.

Carvalho ${ }^{19}$ faz uma análise das diferenças entre os sentidos de liberdade para marcar uma distinção que a posição de Hannah Arendt tem em relação a outros autores. A autora filia seu conceito de liberdade aos filósofos gregos, que ressaltam o seu status político do encontro com outros, em palavras e ações, em um espaço público comum. Sendo assim, seu ponto de vista é o de liberdade como compromisso responsável com o mundo em que vivemos, ao contrário do sentido em que se transmutou na modernidade, que associa liberdade com a ideia de livre-arbítrio, sendo atributo do pensamento, do interior da alma humana, numa atitude solipsista. Esse é designado por Carvalho como "liberdade negativa".

Carvalho analisa a crítica da autora às correntes progressistas, e relaciona seu papel na crise da educação ao representarem tendências que aliam seu pensamento com esse conceito "negativo" de liberdade. Fazemos um contraponto à posição do autor com base nos trabalhos de Brayner ${ }^{21}$, para quem o conceito de liberdade de Paulo Freire tem consonância com o pensamento de Hannah Arendt. Ambos possuem um referencial libertário para a educação, acreditando e apostando no advento do novo como algo transformador do mundo. Para Brayner, dois pontos aproximam as ideias dos autores: a centralidade da noção de mundo para a educação e o conceito de liberdade. Em Freire, o mundo é "aquilo que intermedeia a relação dialogal entre os homens", sendo necessária a sua apreensão para que haja educação, como também defende Arendt. Para os dois autores, o conceito de liberdade está intimamente relacionado à política. A diferença, no que tange a educação, é que...

se em Arendt a política (em sua nostalgia helênica!) já parte do pressuposto da existência de homens livres e plurais, em Freire, não há esse pressuposto: são homens que precisam se libertar pela política, ou melhor, por uma pedagogia que se vê como "ato político"21.

Mais do que às tendências progressistas, a crítica de Hannah Arendt é direcionada aos aspectos das tendências tecnicistas da educação. Estas surgiram com o objetivo de adequar a escola às exigências de 
uma sociedade industrial e tecnológica, cuja ênfase está na preparação de recursos humanos, como mão-de-obra qualificada para a indústria. O conteúdo tem como foco o saber científico e o modelo pedagógico é baseado no taylorismo e na visão tecnocrática de mundo ${ }^{20}$.

A autora questiona as práticas que se baseiam em um pragmatismo necessário para lidar com uma sociedade "de massa", transformando a pedagogia em uma "ciência do ensino em geral a ponto de emancipar inteiramente da matéria a ser ensinada"14. Então, a formação do professor passou a ser o ensino, e não um dos seus domínios. A ênfase não se deu mais no desenvolvimento de conteúdos, mas, sobretudo, no desenvolvimento de habilidades. Baseiam-se nos termos 'competência' e 'capacidade', que, em si, não revelam compromisso ético para além da eficácia, e se baseiam num conceito "negativo" de liberdade ${ }^{19}$.

Um dos pontos mais controversos do pensamento de Hannah Arendt trata da defesa de que a educação deve ser conservadora. O termo costuma ser rejeitado por pedagogos, pois o associa com práticas do chamado modelo tradicional de ensino. No entanto, conservadorismo, para Arendt, tem o sentido de conservação, de "abrigar ou proteger alguma coisa - a criança contra o mundo, o mundo contra a criança, o novo contra o velho, o velho contra o novo"14. Trata-se de preservar a novidade para que a mesma possa ter a possibilidade de, posteriormente, aparecer como inovadora e transformadora.

Nossa esperança está pendente sempre do novo que cada geração aporta; precisamente por basearmos nossa esperança apenas nisso, porém, é que tudo destruímos se tentarmos controlar os novos de tal modo que nós, os velhos possamos ditar sua aparência futura. Exatamente em benefício daquilo que é novo e revolucionário em cada criança é que a educação precisa ser conservadora; ela deve preservar essa novidade e introduzi-la como algo novo em um mundo velho, que, por mais revolucionário que possa ser em suas ações, é sempre, do ponto de vista da geração seguinte, obsoleto e rente à destruição ${ }^{14}$.

\section{Contribuições arendtianas: \\ trazendo outros referenciais teóricos para a educação médica}

Arendt dedicou a maior parte de seus estudos à ação dos homens no mundo, em especial, a práxis política. Para a autora, a política pressupõe ação no espaço público, o lugar onde os seres humanos, como iguais em sua liberdade, se apresentam em ação por meio das palavras e dos gestos.

Arendt faz uma distinção entre os fenômenos pré-políticos (da esfera privada) e os políticos (da esfera pública), situando a educação, assim como a vida em família, entre os primeiros. Ela trata a educação como um atributo da vida de crianças e jovens, numa preparação para a vida política. Para ela, "a educação não pode desempenhar papel nenhum na política, pois, na política, lidamos com aqueles que já estão educados" ${ }^{14}$. Carvalho ${ }^{19}$ ressalta que não se trata de uma posição ingênua de que todo o processo decisório sobre a educação não passaria por disputas políticas, mas da distinção das "naturezas das relações que se estabelecem na esfera pública das que regulam as interações entre professores e alunos".

Sua insistência em distinguir esses dois âmbitos de atividades - o da educação e o da política - não deve ser compreendida, portanto, como o estabelecimento de uma independência de um em relação ao outro, mas simplesmente como uma distinção relacional ${ }^{19}$.

O autor corrobora o sentido político da educação arendtiana quando esta evoca a responsabilidade pelo mundo, ao assegurar sua renovação, e a possibilidade de transformá-lo.

A educação é o ponto em que decidimos se amamos o mundo o bastante para assumirmos a responsabilidade por ele e, com tal gesto, salvá-lo da ruína que seria inevitável não fosse a renovação e a vinda dos novos e dos jovens. A educação é, também, onde decidimos se 
amamos as nossas crianças o bastante para não expulsá-las do nosso mundo e abandonálas a seus próprios recursos, e tampouco arrancar de suas mãos a oportunidade de empreender alguma coisa nova e imprevista para nós, preparando-as em vez disso com antecedência para a tarefa de renovar um mundo comum ${ }^{14}$.

A partir dessa citação se firma a perspectiva de um compromisso ético-político na formação, elemento que ganha potência na aproximação do pensamento arendtiano à educação médica.

Ao admitirmos que a educação seja um fenômeno pré-político, da esfera privada, quando abordamos, então, a formação superior, podemos considerá-la como um momento de passagem para a esfera política, onde os pressupostos sobre educação que trouxemos até agora dialogam com categorias como liberdade, ação, responsabilidade e julgamento. Deste modo, elencamos alguns elementos no pensamento arendtiano como contribuições ao debate do campo da educação, resgatando sua consideração de que o ensino técnico ou superior "é uma espécie de especialização". Visa introduzir o jovem em um segmento limitado e particular do mundo ${ }^{14}$.

Resgatando as categorias arendtianas mundo e mundanidade, trazemos afirmações de César e Duarte ${ }^{18}$, que, ao se debruçarem sobre esse objeto, ressaltam a perspectiva fenomenológica a que Arendt se filia: "o mundo é uma construção propriamente humana, constituído por um conjunto de artefatos e de instituições duráveis, destinados a permitir que os homens estejam continuamente relacionados entre si".

Sendo assim, "mundo" diz respeito ao que se interpõe entre os homens, numa perspectiva relacional em que a verdade é o que está na aparência e esta se relaciona, através dos nossos sentidos, com as atividades da nossa consciência. Considerando essa acepção de constante criação e recriação de mundo, vale ressaltarmos algumas características do mundo moderno de importância para debates com futuros médicos, que dizem respeito a sua futura profissão e relação com a sociedade.

Desde a época em que a autora produziu seus escritos sobre educação, no final da década de 1950, o mundo ocidental caminhou a passos largos para uma sociedade baseada no consumo e na cultura de massa. Mostrou que ainda pode voltar a ter regimes ditatoriais como recentemente em países da América Latina, notadamente no Brasil onde a ditadura militar torturou e matou grande parte de uma geração de jovens que lutavam por uma sociedade mais justa e democrática. As guerras ainda são uma realidade no mundo, e problemas como pobreza e desigualdades sociais são desafios que se apresentam na atualidade.

Vivemos num mundo onde a concepção de indivíduo é hegemônica ao se considerar o ser humano em sociedade. Essa categoria é pensada por Dumont ${ }^{22}$ para descrever o sentido liberal, do ser em si mesmo, em contraposição à noção de pessoa que traz o caráter essencialmente relacional de sua existência. A perspectiva individualista não favorece a possibilidade de um mundo compartilhado. É como se o homem fosse um ser apolítico, incapaz de constituir um espaço público comum.

Em A Condição Humana, Arendt ${ }^{16}$ põe em evidência a distorção em que vivemos desde o advento da modernidade, onde o mais relevante é o que representamos e temos ("o que") e não o que somos e fazemos ("quem"). E quando perguntamos quem é determinada pessoa, traduzimos por o que ela é16. Esse debate incide de maneira central na medicina e em sua formação. Quando perguntamos "quem é o Dr.", não nos concentramos nas suas ações - se ele faz seu trabalho no sentido da justiça e da igualdade - mas no que ele tem - ele é médico especialista, com pós-graduação, premiado por sua sociedade de especialidade etc. O status do médico atualmente é mais valorizado pelos estudantes que o que eles efetivamente realizam com suas palavras e gestos.

Essa perspectiva, amplificada com o advento da modernidade, aproxima-se da ideia de racionalidade científica moderna, traduzida, em nossa área de análise, pela biomedicina ${ }^{23}$.

O estudante de medicina é então imerso em uma visão mecanicista, onde o corpo humano se objetifica em uma máquina, em que as reações fisiopatológicas determinam as doenças, que são, em última análise, a categoria central do trabalho médico. É para a doença que as ações se dirigem, numa tentativa de detectá-las e extirpá-las, abrindo um terreno fértil para as indústrias farmacêutica e de equipamentos, que, mediante estratégias midiáticas de massa, perpetuam esse círculo vicioso que envolve profissionais, instituições formadoras e empresas do setor ${ }^{24}$. Esse sistema tem uma tendência a 
se apresentar burocratizante e autoexplicativo, cujo principal desdobramento consiste na progressiva medicalização da vida em sociedade e a ideia de que cada um é "culpabilizado" por seu adoecimento, num padrão baseado no consumo de produtos e serviços.

Esse mundo precisa ser apresentado ao estudante de medicina, que deve compreendê-lo como processo e construção humanos. É importante a compreensão do advento da biomedicina, e suas repercussões no complexo médico-industrial, como uma construção social, e não uma realidade imutável reificada e, sobretudo, de que esse mundo pode ser diferente, a depender da liberdade que os próprios homens exercitem para construir algo novo.

Dessa concepção, torna-se fundamental que, nos currículos dos cursos de medicina, por exemplo, seja apreendida a realidade local em que vive o povo, sua cultura e sua história. Da escravidão dos negros africanos e quase extermínio dos povos indígenas no Brasil colonial, até a realidade de migrações, exploração do trabalho e ocupação desordenada das áreas de periferia das grandes cidades. Como vivem e em que circunstâncias adoecem essas populações. Ao mesmo tempo, é importante que alunos e instituições formadoras vivenciem o cotidiano do sistema de saúde brasileiro, compreendendo sua atual conformação, o Sistema Único de Saúde, que também consiste em uma construção social, uma conquista da população, num processo imbricado com a democratização do país.

A reflexão sobre o mundo em que vivemos, com especial atenção para a realidade brasileira e o nosso sistema de saúde, se torna então, na perspectiva arendtiana, uma ação responsável dos professores com o futuro dos alunos e com a constituição desse próprio mundo.

Ao apresentarem esse mundo, sob forma de memória, de histórias do nosso tempo, os professores devem estar atentos para o fato de que são exemplos para os futuros médicos. E, para uma formação com base ético-política, os exemplos são mais valiosos que códigos de conduta a que são submetidos os profissionais médicos. Para isso, é necessária a autoridade dos professores, no sentido arendtiano, legítima, conquistada pelo reconhecimento. No entanto, a crise da modernidade traz como elemento a crise de autoridade e, nos cursos de medicina, estas rupturas se tornam evidentes ao percebermos desde despreparo pedagógico do corpo docente até distorções de princípios éticos em parte dos professores.

A perda da autoridade, que se apresenta na formação em medicina, tem efeitos devastadores: se os que ensinam não têm conhecimento suficiente do mundo e não obtêm reconhecimento frente a seus educandos, ficamos às cegas na constante reprodução de uma cultura médica (biomedicina) que não enxerga a liberdade como ação e criação do novo, assemelhando-se, em sua característica uniformizante, às culturas de massa, padronizando as pessoas e desconsiderando-as por trás de suas doenças. Doenças sem rosto, pessoas cujas histórias são recortadas pelo viés de sua patologia. Desta forma, parece mais difícil produzir um senso de responsabilidade por algo (e não alguém) que não se vincula, que não se reconhece.

Partindo do entendimento de que, ao iniciar a graduação, o jovem já adentra a esfera pública, da vida política, essa deve conciliar esses dois aspectos: liberdade e responsabilidade. Tendo noção do sentido que Arendt dá ao termo liberdade, é importante entendê-la como constituinte da política, ou seja, sem liberdade "a vida política seria destituída de significado". Para ela, a razão de ser da política é a liberdade e "seu domínio de experiência é a ação"14. Na filosofia de Arendt, esses três termos liberdade, ação e política - estão amalgamados, possibilitando compreender a condição eminentemente humana do sujeito em sua singularidade na relação com o outro, na ação em meio à pluralidade do homem no mundo.

Esse referencial nos permite questionar, no campo da formação e da prática médicas, uma "autonomia profissional", onde o médico teria o livre-arbítrio no cotidiano de sua atuação. Uma ação autônoma, baseada na liberdade de decisão solitária, pode produzir uma ação sem limite, desconectada dos outros e do mundo. Se as ações em saúde se apresentam enquanto práxis - atividade humana contextualizada -, não podem ser somente autônomas, pois precisam estar inseridas em um espaço comum, de diálogo, de trocas e de compartilhamento com os outros. Deve haver, então, envolvimento do médico com a equipe de saúde, com gestores e, sobretudo, com os pacientes e familiares.

São exemplos da ação política do médico, e que devem fazer parte de sua formação: o trabalho em equipe, o vínculo e a corresponsabilidade com as pessoas a quem assiste, numa perspectiva baseada no cuidado e na constituição de horizontes terapêuticos comuns ${ }^{25}$, onde esses outros atores 
necessariamente participam das decisões. Neste diálogo podem estar presentes diferentes formas de compreender e vivenciar o processo de adoecimento. Atuar com liberdade nesse espaço público é ter a possibilidade da construção de uma outra forma de se relacionar com a equipe, que não seja baseada em concepções e atos corporativos, mas solidários e éticos. Da mesma maneira também com os pacientes, não na forma de imposição da perspectiva biomédica, mas levando em consideração como vivem a vida, a cultura, e a experiência de adoecimento dos mesmos.

É nesse ponto que a ideia de educação conservadora de Hannah Arendt pode nos auxiliar a compreender as tensões acerca da crise da modernidade e seus efeitos na educação médica. Podemos promover a reflexão crítica, de modo a questionar a hegemonia biomédica, que ensina o corporativismo e a "autonomia" inseridos em uma lógica produtiva que favorece o poder do complexo médicoindustrial, tornando os futuros médicos não seres humanos reflexivos, mas engrenagens dessa lógica medicalizante e desumanizante.

Papadimos $^{26}$, em uma das únicas publicações da área da educação médica que lida com categorias propriamente arendtianas, caminha no mesmo sentido, apresentando a necessidade de se trabalhar o pensamento reflexivo durante o processo formativo, com o objetivo de evitar que os médicos simplesmente aceitem o cientificismo que lhes é inculcado, sem a capacidade crítica de análise. Papadimos $^{26}$ ressalta que o pensamento reflexivo auxilia os futuros médicos a desenvolver sua singularidade, manifestada em suas palavras e ações. Ajuda a mudar o foco de importância, dado pelo estudante, do "que" eles próprios são para "quem" são.

Nessa mesma linha de pensamento, ressaltamos outra contribuição da autora para os processos formativos na medicina, que dizem respeito a valores e atitudes: as reflexões sobre a responsabilidade e o julgamento escritas a partir do acompanhamento do julgamento de Eichmann ${ }^{15}$ e que podem se aplicar a diversas áreas, incluindo a medicina.

Ao decidir acompanhar o julgamento, Arendt supôs que fosse encontrar um tirano em pessoa, mas, para sua surpresa, ele não passava de um homem comum, um burocrata, cumpridor de ordens, que era incapaz de pensar e refletir sobre o que estava fazendo. Arendt cunhou então a expressão "banalidade do mal" se referindo às ações de uma "compacta massa burocrática de homens perfeitamente normais, desprovidos da capacidade de pensar, de submeterem os acontecimentos a juízo" ${ }^{27}$. Eichmann ${ }^{15}$ justificava seus atos com o discurso carregado de clichês, de que estava apenas cumprindo ordens. Ou seja, não passava de mais um burocrata a serviço do sistema, onde, se não fosse ele, seria outro.

Nessa análise Arendt relacionou a posição do oficial com a metáfora do "dente da engrenagem". O sistema seria a engrenagem e os seus executores seriam os "dentes", que, por não serem capazes de pensar, apenas ajudariam a impulsionar o sistema, não importando os seus fins. Colocando a culpa no sistema, Eichmann tentou se eximir da sua responsabilidade, pois se todos são culpados, ninguém o é. Arendt reforça que o oficial nazista tinha responsabilidade pessoal sobre os seus atos, pois o mesmo tinha a possibilidade de escolha de não fazer, mesmo que fosse punido por isso ${ }^{15}$.

A ideia da falta de juízo crítico e a burocratização das relações está presente em diversos setores da sociedade, não sendo diferente na medicina. Pode ser difícil aceitar, mas observa-se que boa parte dos médicos é incapaz de refletir sobre o que está fazendo no cotidiano, faltando-lhes juízo crítico frente a situações que envolvem seus pacientes. Isso acontece quando se prescreve uma medicação que o paciente é incapaz de adquirir ou fazer uso; ou quando atendemos um morador da região rural ou ribeirinha e o encaminhamos para uma unidade de referência que fica a dias de barco, muitas vezes sem necessidade; ou, ainda, quando não respeitamos sua cultura e impomos mudanças de comportamento de acordo com o referencial biomédico. Acontece, também, quando coloca a culpa no sistema de saúde por uma falha ou como justificativa para o não-uso de todo o seu potencial, que pode variar da negação de um atendimento até a obediência cega a regras operacionais. Mas essa ideia de Hannah Arendt se aplica, especialmente, quando o médico exerce sua prática sem um pensamento crítico sobre o modelo biomédico, permanecendo limitado em suas ações e não conseguindo responder adequadamente às necessidades das pessoas.

A teoria do dente de engrenagem pode servir de alerta para refletir o nosso papel diante da responsabilidade pessoal e coletiva nas práticas cotidianas nas instituições de saúde. Acolhimento, vínculo, humanização e cidadania não podem ser meros jargões no planejamento das políticas, mas um 
constante exercício de evocar a responsabilização como elemento virtuoso das ações de um cuidado como valor $^{28}$. Para Arendt, a responsabilidade pessoal não pode ser transferida para um sistema, apesar de não se poder desconsiderar a maneira como esse sistema opera ${ }^{15}$.

As instituições e os processos de formação têm forte implicação nessa situação, pois reproduzem um sistema de pensamento burocratizante e autoexplicativo. Para burocratizar o trabalho do médico, desenvolve-se um processo de formação baseado em um universo de saberes e práticas uniformizantes, e embota-se sua capacidade de se afetar e de pensar de maneira crítico-reflexiva. Um dos desdobramentos disso é a progressiva medicalização da vida em sociedade e a ideia de que cada um é "culpabilizado" por seu adoecimento, num padrão baseado no consumo de produtos e serviços, que exime os médicos da responsabilidade daquele a quem assiste.

Agir com liberdade para criar o novo é necessariamente agir tendo consciência de sua responsabilidade em não reproduzir uma lógica em que as vozes daqueles que são a razão de ser da profissão não são efetivamente ouvidas, não aparecem diante das vozes hegemônicas do campo. Agrega também o sentimento de responsabilidade pelo cuidado, instaurando uma relação de confiança onde a pessoa se sinta segura e amparada em seu adoecimento. Outrossim, é também uma responsabilidade com o funcionamento dos serviços de saúde onde atua e com o sistema como um todo.

Andrade ${ }^{29}$, ao analisar as contribuições de Hannah Arendt para o campo da educação a partir da reflexão sobre a banalidade do mal, aponta a tarefa educativa de se trabalhar com o pensamento, pois um dos principais determinantes de um comportamento como o de Eichmann seria a incapacidade de pensar. $\mathrm{O}$ autor trabalha sobre os escritos de $A$ vida do espírito ${ }^{30} \mathrm{e}$, a partir desse referencial, defende que o pensamento não deve se interessar pela verdade das coisas, e sim pelo que elas significam para nós. Desta forma, propõe uma tarefa educativa numa perspectiva ético-política comprometida com valores como justiça, igualdade, solidariedade, diálogo e tolerância.

\section{Considerações finais}

As DCN para os cursos de medicina definem, claramente, a importância de um profissional com formação crítica e reflexiva, com senso de responsabilidade social e compromisso com a cidadania ${ }^{6}$. A partir dessa necessidade, o pensamento de Hannah Arendt e seus desdobramentos para a ação podem contribuir com novos aportes teóricos que visam a consolidação das mudanças na educação médica. A transformação depende, então, de quanto somos responsáveis pelo desenvolvimento da prática profissional e de valores desses jovens que estão no caminho entre a educação e a ação política. Se desejamos o exercício da medicina como cuidado em saúde, como ação política, como cultivo da liberdade enquanto sentimento público, é necessário que denunciemos os processos de coerção pelos quais passam os futuros médicos durante o seu processo de formação, e criemos momentos para reflexão sobre as ações.

Esses momentos podem advir do cultivo de verdadeiros espaços públicos em sala de aula, onde, a partir de metodologias ativas organizadas pelos professores, com autoridade legítima, possa emergir a pluralidade existente entre os estudantes. Onde os mesmos possam refletir sobre a realidade, com a imersão em novos cenários de aprendizagem, nas capitais e no interior. E que essas experiências possam afetar, de alguma forma, com ajuda dos professores, a sua atitude frente ao mundo e a prática médica, na formação do senso de responsabilidade com o outro, com seu trabalho e com a sociedade.

Ainda assim não teremos garantias da transformação no futuro, pois a criação do novo incorre em liberdade e risco - em crises - não em certezas. Ao menos, assim, colocamos o surgimento de uma nova educação e prática médicas no campo das possibilidades. 


\section{Colaboradores}

Os autores trabalharam juntos em todas as etapas de produção do manuscrito.

\section{Referências}

1. Garcia JC. La educación médica en la América Latina. Washington: OPAS/OMS; 1972.

2. Carvalho JSF. Hannah Arendt e a Educação. Atta: mídia e educação, produção em vídeo. 2011.

3. Luz MT. Fragilidade social e busca por cuidado na sociedade civil de hoje. In: Pinheiro R, Mattos RA, organizadores. Cuidado: as fronteiras da integralidade. Rio de Janeiro: Hucitec; 2004. p. 9-20.

4. Vianna CMM. Estruturas do Sistema de Saúde: do complexo médico-industrial ao médico-financeiro. Physis. 2002; 12(2):375-90.

5. Lampert JB. Tendências de Mudanças na formação médica no Brasil. São Paulo: Hucitec, Associação Brasileira de Educação Médica; 2002.

6. Conselho Nacional de Educação. Resolução CNE/CES no 4, de 7 de Novembro de 2001. Institui Diretrizes Curriculares Nacionais do Curso de Graduação em Medicina. Brasília, DF: CNE; 2001

7. Silveira R, Pinheiro R. Em busca da integralidade na formação médica: revisitando as experiências no ensino de graduação em medicina. In: Pinheiro R, Silva Júnior AG, organizadores. Por uma sociedade cuidadora. Rio de Janeiro: IMS/UERJ, Cepesc, Abrasco; 2010. p. 333-48.

8. Marsiglia RG. Relação ensino/serviços: dez anos de integração docente-assistencial IDA no Brasil. São Paulo: Hucitec; 1995.

9. Kisil M, Chaves M. Programa UNI: uma nova iniciativa na educação dos profissionais de saúde. Battle Creek: Fundação W. K. Kellogg; 1994.

10. Costa HOG, Feuerwerker LCM, Rangel ML. Diversificação de cenários ensino e trabalho sobre necessidades/problemas da comunidade. Divulg Saúde Debate. 2000; 22:25-35.

11. Cruz KT. A formação médica no discurso da CINAEM [dissertação]. Campinas: Unicamp; 2004.

12. Pinheiro R, Ceccim RB, Mattos RA, organizadores. Ensinar Saúde: a integralidade e o SUS nos cursos de graduação na área da saúde. Rio de Janeiro: IMS/UERJ, Cepesc, Abrasco; 2006.

13. Pinheiro R, Mattos RA, organizadores. Os sentidos da integralidade na atenção $e$ no cuidado à saúde. Rio de Janeiro: IMS-UERJ; 2001.

14. Arendt H. Entre o passado e o futuro. 6a ed. São Paulo: Perspectiva; 2009.

15. Arendt H. Responsabilidade e julgamento. São Paulo: Companhia das Letras; 2004.

16. Arendt H. A condição humana. 8a ed. Rio de Janeiro: Forense Universitária; 1997.

17. Carvalho JSF. Acolher o mundo: educação como iniciação nas heranças simbólicas comuns e públicas. In: Barbosa RLL, organizador. Formação de educadores: artes e técnicas. São Paulo: Ed. Unesp; 2006. p. 61-72.

18. César MRA, Duarte A. Hannah Arendt: pensar a crise da educação no mundo contemporâneo. Educ Pesqui. 2010; 36(3):823-37.

19. Carvalho JC. A liberdade educa ou a educação liberta? Uma crítica das pedagogias da autonomia à luz do pensamento de Hannah Arendt. Educ Pesqui. 2010; 36(3):839-51. 
20. Aranha MLA. Filosofia da educação. 2a ed. São Paulo: Moderna; 1990.

21. Brayner FHA. Um mundo entre os homens (um confronto entre Hannah Arendt e Paulo Freire). In: Anais da 32a Reunião Anual da ANPED - Sociedade, cultura e educação: novas regulações; 2009; Caxambu. Caxambu; 2009. [acesso 2012 Set 20]; Disponível em: http://www.anped.org.br/reunioes/32ra/trabalho_gt_06.html

22. Dumont L. O individualismo: uma perspectiva antropológica da ideologia moderna. Rio de Janeiro: Rocco; 1985.

23. Luz MT. Natural, racional, social: razão médica e racionalidade científica moderna. Rio de Janeiro: Campus; 1988.

24. Luz MT. As instituições médicas no Brasil: instituição e estratégia de hegemonia. Rio de Janeiro: Graal; 1979.

25. Ayres JRCM. Cuidado e reconstrução das práticas de Saúde. Interface (Botucatu). 2004; 8(14):73-92.

26. Papadimos TJ. Reflective thinking and medical students: some thougtful distillations regarding John Dewey and Hannah Arendt. Philos Ethics Human Med. 2009; 4(1):5-14.

27. Assy B. Introdução à edição brasileira "Faces privadas em espaços públicos": por uma ética da responsabilidade. In: Arendt $\mathrm{H}$, organizadora. Responsabilidade e julgamento. São Paulo: Companhia das Letras; 2004. p. 31-60.

28. Stelet $B P$, Pinheiro R. Da filosofia moral ao amor ao mundo: contribuições arendtianas por uma ética do cuidado em saúde. In: Pinheiro R, Silva Júnior AG, organizadores. Cidadania no cuidado: o universal e o comum na integralidade das ações de saúde. Rio de Janeiro: IMS/UERJ, Cepesc, Abrasco; 2011. p. 45-69.

29. Andrade M. A banalidade do mal e as possibilidades da educação moral: contribuições arendtianas. Rev Bras Educ 2010; 15(43):109-25.

30. Arendt H. A vida do espírito. 3a ed. Rio de Janeiro: Relume Dumará; 1995.

Silveira RP, Stelet BP, Pinheiro R. ¿Crisis en la educación médica? Un ensayo sobre el referencial arendtiano. Interface (Botucatu). 2014; 18(48):115-26.

Se trata de un ensayo que contribuye con el contexto de transformaciones en la educación médica en Brasil a la luz del pensamiento de la filósofa Hannah Arendt. La autora hace una lectura crítica de la modernidad, señalando su contexto de crisis y hasta qué punto ella se refleja en áreas como las de la educación y la política. Partiendo de las reflexiones sobre la crisis en la educación, la ruptura con la tradición y la pérdida de la autoridad, traemos su pensamiento para un análisis sobre la práctica médica y su formación, regidas principalmente por el modelo biomédico y otras manifestaciones del mundo moderno. Finalmente, subrayamos la necesidad de trabajar en la educación médica con categorías como responsabilidad, juicio y pensamiento reflexivo que fueron objetos de análisis de la autora ya en la fase final de su vida.

Palabras-clave: Educación médica. Política. Historia moderna 1601- . 